\title{
A model of the influence of false-positive mammography screening results on subsequent screening
}

\author{
Jessica T. DeFrank ${ }^{*}$ and Noel Brewer \\ Department of Health Behavior and Health Education, UNC Gillings School of Global Public \\ Health, 325 Rosenau Hall, CB\# 7440, Chapel Hill, NC 27599, USA
}

\begin{abstract}
Decades of empirical research have demonstrated psychological and behavioural consequences of false-positive medical tests. To organise this literature and offer novel predictions, we propose a model of how false-positive mammography results affect return for subsequent mammography screening. We propose that false-positive mammography results alter how women think about themselves (e.g., increasing their perceived likelihood of getting breast cancer) and the screening test (e.g., believing mammography test results are less accurate). We further hypothesise that thoughts elicited by the false-positive experience will, in turn, affect future use of screening mammography. In addition, we discuss methodological considerations for statistical analyses of these mediational pathways and propose two classes of potential moderators. While our model focuses on mammography screening, it may be applicable to psychological and behavioural responses to other screening tests. The model is especially timely as false-positive medical test results are increasingly common, due to efforts to increase uptake of cancer screening, new technologies that improve existing tests' ability to detect disease at the cost of increased false alarms, and growing numbers of new medical tests.
\end{abstract}

\section{Keywords}

cancer screening; mammography; psychological outcomes; false-positive; health behaviour

\section{Introduction}

False-positive screening mammography results are surprisingly common. An abnormal mammography result is false-positive if follow-up tests do not indicate breast cancer (Brewer, Salz, \& Lillie, 2007). Between 6 and 15\% of screening mammograms in the USA are abnormal, and most of these are false-positives (Mushlin, Kouides, \& Shapiro, 1998; Smith-Bindman et al., 2003; Yankaskas et al., 2004). For this reason, about one-half of US women can expect to have a false-positive mammogram result if screened regularly over 10 years (Elmore et al., 1998). False-positive mammograms are less common in other countries, but rates still range from 1 to $9 \%$ (Elmore et al., 2003; Yankaskas et al., 2004).

\footnotetext{
(C) 2010 Taylor \& Francis

*Corresponding author. defrank@email.unc.edu.

Publisher's Disclaimer: Full terms and conditions of use: http://www.informaworld.com/terms-and-conditions-of-access.pdf This article may be used for research, teaching and private study purposes. Any substantial or systematic reproduction, re-distribution, re-selling, loan or sub-licensing, systematic supply or distribution in any form to anyone is expressly forbidden.

The publisher does not give any warranty express or implied or make any representation that the contents will be complete or accurate or up to date. The accuracy of any instructions, formulae and drug doses should be independently verified with primary sources. The publisher shall not be liable for any loss, actions, claims, proceedings, demand or costs or damages whatsoever or howsoever caused arising directly or indirectly in connection with or arising out of the use of this material.
} 
False-positives are also common for other tests that screen for prostate, lung (Croswell et al., 2009) and cervical cancer (Nanda et al., 2000).

False-positive screening mammograms incur substantial financial costs associated with follow-up testing, estimated to be over US\$100 million annually in the USA alone (Cyrlak, 1988). Follow-up tests can be as benign as having another mammogram or as invasive as an excisional biopsy, which is conducted in an operating room. In a recent meta-analysis, we found that false-positives also have small but reliable effects on women's breast cancerrelated worry, anxiety, distress and perceptions of breast cancer risk even several years later (Salz, Richman, \& Brewer, 2010). Our other meta-analysis of long-term behavioural effects found that false-positive screening mammography results motivated future mammography screening for some women, but deterred future screening for others (Brewer et al., 2007).

The purpose of this article is to present a model of how false-positive screening mammography results influence return for routine mammography screening. We focus on mammography, because false-positive results are a common experience, and almost all studies of psychological and behavioural effects of false-positives come from the mammography literature. We present an overview of the model and then present empirical and theoretical support for the main pathways of the model and derive novel predictions. We also discuss the methodological and statistical considerations when examining the relationship between false-positive mammography results and future screening behaviour. Furthermore, we focus on false-positive results on routine screening mammograms, but not on diagnostic mammograms prompted by breast cancer symptoms. Henceforth, we refer to routine screening mammograms as mammograms for the sake of simplicity, but this is not meant to include diagnostic testing.

\section{Overview of theoretical model}

We propose that false-positive mammography results should cause women to have greater breast cancer-related worry, anxiety and increased perceptions of breast cancer risk (Figure 1). These thoughts, in turn, should motivate vigilance about future mammography. We also propose that women may experience positive consequences after receipt of false-positive results, such as thinking more about the benefits of regular screening. Increased thought about the benefits of mammography should make women more likely to adhere to future screening. At the same time, false-positive mammography results might cause some women to believe abnormal test results are less accurate. This belief may cause women to distrust mammography, deterring them from returning for future screening. Thus, the model suggests the relationship between receipt of false-positive mammography results and return routine screening is mediated through women's thoughts about themselves (worry, anxiety and perceptions of breast cancer risk) and thoughts about the screening test (thinking about the benefits of regular screening and beliefs about the test's accuracy). We describe in greater detail in the next section each of these thoughts and their associations with future screening behaviour.

Abnormal results on credible medical tests are difficult to ignore, even after people receive subsequent normal results. Implicit in the model is the assumption that thoughts elicited by abnormal mammography test results may persist long after the cancer has been ruled out, having unintended consequences on future screening behaviour. One argument for the persistence of such thoughts is that people may have considerable difficulty revising their beliefs once they are formed (Gilbert, Tafarodi, \& Malone, 1993; Lord, Ross, \& Lepper, 1979). That is, the abnormal mammography test results might cause women to believe they have an underlying medical problem. Upon learning they do not have cancer, some women may have difficulty undoing thoughts of worry, anxiety and breast cancer risk elicited by the 
experience (c.f., Randall, Molloy, \& Steptoe, 2009; Thoolen, De Ridder, Bensing, Gorter, \& Rutten, 2008).

The model also assumes that psychological responses to false-positive test results are disease specific. That is, the reaction to false-positive mammography results should be specific to breast cancer (e.g., worry about breast cancer) but not general (e.g., generalised anxiety). This specificity assumption is robustly supported in the mammography literature (Brodersen \& Thorsen, 2007; Brodersen, Thorsen, \& Cockburn, 2004; Salz et al., 2010).

\section{Influence of false-positive mammography results on subsequent screening}

Empirical studies show that false-positive mammography results influence future screening behaviours. Our recent meta-analysis of studies including over 300,000 women from the USA, Canada and Europe showed that the false-positive mammography results affected return for routine mammograms (Brewer et al., 2007). The direction of this finding differed by geographic region. In the USA (5 studies), women who received false-positive results were slightly (7\%) more likely to return for subsequent screening mammograms compared to women who had normal mammogram results. In contrast, studies conducted in European countries ( 5 studies) generally found no effect of false-positive mammograms on return for screening, though fixed effects statistical analysis of the data suggested a small reduction in return for screening with false-positive results. Studies conducted in Canada (2 studies) also found that women who received false-positive results were less likely to return for subsequent screening. Studies published after the meta-analysis generally confirm these findings (Andersen, Vejborg, \& von Euler-Chelpin, 2008; Brain et al., 2008; Decker, 2008). While most of the evidence for this relationship comes from the mammography screening literature, false-positive test results also affect return for prostate (Ford, Havstad, Demers, \& Cole Johnson, 2005), lung (Ford, Havstad, Flickinger, \& Johnson, 2003), and cervical cancer screening (Lerman, Miller et al., 1991).

Findings from our meta-analyses also offer potential insight into what a plausible theory might look like. The theory must account for psychological processes that increase likelihood of return for screening after a false-positive experience, as typically found for USA studies. The theory would also have to account for psychological processes that have the opposite effect on return for screening, as typically found for European and Canadian mammography studies. Although several system-level factors offer potential explanations for conflicting geographical findings (Brewer et al., 2007), the model presented here is not intended to explain geographical differences in return for screening, but rather focuses on psychological reactions to false-positive experiences that motivate or interfere with future screening.

\section{False-positive mammography results and thoughts about the person}

\section{Worry}

It is reasonable to expect that receiving an initially abnormal test result would cause people to worry about disease. We define worry for the purpose of our model as ruminative thinking about a negative or potentially dangerous event. Researchers also describe worry as being a combination of 'unwanted cognitive activity' and emotion (McCaul \& Mullens, 2003). Numerous studies show that false-positive mammography results cause worry about breast cancer that persists long after the cancer has been ruled out (Aro, Pilvikki Absetz, van Elderen, van der Ploeg, \& van der Kamp, 2000; Brewer et al., 2007; Lerman, Trock, Rimer, Boyce et al., 1991; Lerman, Trock, Rimer, Jepson et al., 1991; Lipkus, Halabi, Strigo, \& Rimer, 2000; Rimer \& Bluman, 1997; Scaf-Klomp, Sanderman, van de Wiel, Otter, \& van den Heuvel, 1997). Studies by Lerman, Trock, Rimer, Boyce et al. (1991) and Lerman, 
Trock, Rimer, Jepson et al. (1991), among the earliest to investigate long-term effects of false-positive mammograms, found higher levels of worry for women who received falsepositive test results compared to those who received normal test results 3 months after the screening exam. Aro and colleagues (2000) followed women prospectively and found moderately elevated worry for women who had false-positive mammography results compared to those who had normal test results both at 2 and 12 months. A study in the UK, where routine screening is recommended every 3 years, found that women who received previous false-positive results continued to experience psychological distress in the month prior to their next routine screening exam (Brett \& Austoker, 2001).

While worry can be aversive, its influence on health behaviour may be positive. Nonpathological worry should motivate protective health behaviours (Leventhal, Brissette, \& Leventhal, 2003). Worry about breast cancer motivates breast cancer screening in the general population (Consedine, Magai, Krivoshekova, Ryzewicz, \& Neugut, 2004; Hay, McCaul, \& Magnan, 2006), and this is also true for women who received false-positive mammography results. Lerman, Trock, Rimer, Boyce et al., 1991 showed that higher worry about breast cancer after a false-positive experience was associated with a greater likelihood of return for routine screening. The authors speculated that women might seek to resolve their feelings of worry through heightened vigilance about breast screening. While it is plausible that worry after false-positive test results could deter future screening (Brett, Bankhead, Henderson, Watson, \& Austoker, 2005; Consedine et al., 2004) or might have a curvilinear relationship with screening (i.e., some research suggests that moderate levels of worry motivate screening, whereas extremely high or low levels of worry deter future screening) (Andersen, Smith, Meischke, Bowen, \& Urban, 2003), the research literature does not offer much support for these predictions.

\section{Anxiety}

Although some use the terms worry and anxiety interchangeably, anxiety is often conceptualised as a distinct phenomenon that is more clearly affective, characterised by intense and uncontrollable emotional and physiological responses to a perceived threat (McCaul \& Mullens, 2003). While worry and anxiety may be conceptually separable, association between false-positive mammography results and breast cancer-specific anxiety are similar to those for worry (Gram, Lund, \& Slenker, 1990; Lampic, Thurfjell, Bergh, \& Sjoden, 2001; Lampic, Thurfjell, \& Sjoden, 2003; Lerman, Trock, Rimer, Boyce et al., 1991). For example, Gram and colleagues (1990) found $29 \%$ of women who had falsepositive mammography results reported elevated breast cancer-related anxiety 18 months after screening compared to $13 \%$ of women who had normal results. Similar to the behavioural effects of worry, elevated anxiety about breast cancer should motivate return for routine mammography screening.

\section{Perceived likelihood}

Many women who have received false-positive mammography results report higher estimates of their chances of getting breast cancer than those whose mammography results were normal. Aro and colleagues (2000) found 54\% of women who received false-positive mammography results described their likelihood of future disease as 'high' or 'very high' 1 year after the false-positive result, higher than the percentage of women who received normal results (43\%). Lipkus and colleagues (2000) reported similar findings, such that women who received false-positive mammography results perceived their lifetime breast cancer risk as higher than women whose results were normal regardless of the number of years elapsed since the false-positive result. As most abnormal mammograms do not indicate increased breast cancer risk (Christiansen et al., 2000), women's perceptions of having an increased likelihood for breast cancer after receiving false-positive results are 
often inaccurate. Higher perceived risk should motivate return for mammography (Vernon, 1999). Findings from two large meta-analytic reviews found that greater perceived likelihood of breast cancer was associated with increased screening in the general population, although effect sizes were often small (Katapodi, Lee, Facione, \& Dodd, 2004; McCaul, Branstetter, Schroeder, \& Glasgow, 1996). The link between perceived likelihood of disease and protective behaviour is also central to several common models of health behaviour (Janz \& Becker, 1984; Weinstein \& Sandman, 1992; Witte, 1992).

\section{False-positive mammography results and thoughts about the screening test}

We also propose that false-positive mammography results will cause women to think differently about mammography screening. Some women might cope with the worry and anxiety elicited by false-positive results by thinking more about the benefits of regular screening. Conversely, some women who receive false-positive results might question the accuracy of screening, causing them to distrust the test. We propose that these two types of thoughts have opposite effects on return for subsequent mammography screening.

\section{Thinking about the benefits of screening}

While false-positive mammography results cause breast cancer-related distress, evidence suggests that false-positives also increase rumination on screening's benefits (Brodersen \& Thorsen, 2008; Lipkus et al., 2000; Pisano, Earp, \& Gallant, 1998; Salz et al., 2010). Commonly anticipated benefits to getting mammograms include that they offer the possibility of early detection, save lives and provide 'peace of mind'. Thinking about the benefits of screening may serve as a coping response for people who previously experienced false-positive results (Lazarus, 1984). Evidence supporting this argument comes from a recent national survey in the USA in which almost all people (98\%) who had false-positive cancer screening test results remained enthusiastic about the benefits of screening even though many also reported that the experience was 'very scary' or the 'scariest time of my life' (Schwartz, Woloshin, Fowler, \& Welch, 2004). Clinicians report a similar phenomenon for abnormal prostate cancer tests (Ransohoff, McNaughton Collins, \& Fowler, 2002).

The increased consideration of the potential benefits of screening should make these specific beliefs more accessible in memory and thus more able to affect subsequent behaviour (Morwitz \& Fitzsimons, 2004; Strack \& Mussweiler, 1997). Studies show that women who endorse more benefits of mammography are likely to be screened more regularly (Champion et al., 2003; Greene, Torio, \& Klassen, 2005; Mayne \& Earp, 2003). As a result, many interventions designed to increase mammography use focus on getting women to think about the test's benefits (Champion et al., 2003; Rauscher, Earp, \& O'Malley, 2004; Rimer et al., 1996).

\section{Perceptions of test accuracy}

One potentially important but largely ignored area of research is the impact of false-positive results on perceptions of test accuracy. We focus on beliefs about a test's sensitivity and positive predictive value. Sensitivity is the probability an individual with disease will receive a positive test result. Mammography will detect between $83 \%$ and $95 \%$ of breast cancers in women who have the disease (Mushlin et al., 1998). Another measure of screening accuracy, positive predictive value, is the probability a positive test result has correctly detected disease. Only about $10 \%$ of abnormal mammograms result in a cancer diagnosis (Kerlikowske et al., 1993). The small number of breast cancer cases causes the ratio of true positives to total positives (positive predictive value) to be low whereas the ratio of false-positives to total positives is high (Gigerenzer \& Edwards, 2003). 
More importantly for our model, however, are women's perceptions of these concepts. We propose that women who experience false-positives should be more likely to understand that abnormal test results do not always indicate presence of disease (test's positive predictive value). However, receipt of false-positive results should have no impact on women's perceptions of mammography's accuracy for detecting disease when it is present (test's sensitivity). Similarly, false-positive experiences should have no effect on women's beliefs about mammography's effectiveness for reducing breast cancer deaths. Few studies have explored perceptions of screening accuracy and effectiveness after false-positive experiences (Aro et al., 2000; Bull \& Campbell, 1991; Davey et al., 2003). While some evidence suggests that false-positives do not impact women's perceptions of mammography's sensitivity or effectiveness for reducing deaths from breast cancer (Aro et al., 2000; Bull \& Campbell, 1991), no study we are aware of has investigated perceptions of mammography's positive predictive value and impact on use.

Perceptions of a screening test's accuracy should be associated with its use (Aro, de Koning, Absetz, \& Schreck, 1999). We propose that women who believe abnormal test results are less accurate will avoid subsequent screening, although no study has tested this hypothesis. This may be because of women who believe abnormal test results are inaccurate might have feelings of distrust about the test or the medical system. This prediction is supported by qualitative research by Padgett, Yedidia, Kerner, \& Mandelblatt (2001) where many women who received false-positive mammography results left the screening experience feeling suspicious or distrusting of the health care system. Studies show that medical mistrust is associated with underutilisation of health care services (Fiscella, Franks, \& Clancy, 1998; Laveist, Isaac, \& Williams, 2009).

\section{Predictions from the model}

The proposed model yields several novel predictions about the psychological and behavioural effects of false-positive mammography results.

(1) False-positive mammography results should affect adherence to subsequent mammography screening. Findings from studies in the USA, where there is no nationalised mammography screening programme, suggest that women who receive false-positive mammography results should be more likely to return for subsequent mammography screening. Findings from studies in Europe and Canada, where mammography screening is centrally organised and paid for by the state, suggest the opposite effect (Brewer et al., 2007). The prediction that false-positive test results influence future screening behaviour is also supported in the prostate, cervical and lung cancer screening literatures (Ford et al., 2003, 2005; Lerman, Miller et al., 1991).

(2) Thoughts elicited by a false-positive experience should mediate the relationship between receipt of false-positive mammography results and adherence to subsequent screening. Women whose previous mammograms were falsepositive will have elevated breast cancer-related worry, anxiety and will believe they are more likely to get breast cancer compared to women whose previous mammograms were normal. In turn, these thoughts will motivate vigilance about regular screening. Women might also think more about the benefits of regular mammography after receipt of false-positive results, which in turn would also increase their likelihood of return for screening.

(3) Beliefs about mammography's accuracy should suppress the relationship between receipt of false-positive mammography results and adherence to subsequent screening. Women who receive false-positive mammography results may believe that abnormal test results are less accurate. This belief might cause 
women to distrust screening, off-setting the positive influences of worry, perceived likelihood of disease and thoughts about the test's benefits.

\section{Moderating influences of false-positive mammography results on subsequent screening}

While we hypothesise that false-positive mammography results influence subsequent screening - as mediated by women's thoughts about themselves and thoughts about the screening test - important subgroup differences may also exist. We argue for two broad classes of moderators, one that inhibits understanding of test results and another that inhibits action. Each class of moderators is relevant to a different mediational pathway (Figure 2). Thus, additional predictions from the model are as follows:

(4) The effects of false-positive mammography results on subsequent screening depend on people's ability to understand the results. People with lower education levels might understand less of the complexities of medical testing and their test results. As a result, they should be less likely to experience the thoughts typically elicited by false-positives, breaking the mediational pathway. Similar predictions can be made for factors such as numeracy (Peters, Hibbard, Slovic \& Dieckmann, 2007; Reyna, Nelson, Han, \& Dieckmann, 2009) and health literacy (Brewer et al., 2009).

The effects of false-positive mammography results on subsequent screening depend on people's ability to act on the results. People who report financial hardship or lack health care resources may not show the pattern of mediation proposed in the previous model. For example, women who have lower incomes or report cost barriers to screening might not have the means to relieve the feelings elicited by their false-positive experience (i.e., disease-related distress, anxiety and perceived likelihood of disease) by returning for their next regular screening. Women who receive false-positive mammography results are likely burdened with some costs from follow-up testing (although this may be less of an issue outside of the USA where costs are not a barrier to mammography screening). Other costs associated with false-positive test results may include missed work hours, transportation, childcare needs or other inconveniences (Lafata et al., 2004).

Similarly, women who receive false-positive test results and do not have a usual source of health care, or opportunities to communicate with their physicians about their false-positive experiences, may be less likely to comply with future mammography screening compared to women who receive false-positive results but have these resources. Physicians are important sources of information for women contemplating the benefits and risks of screening (Meissner, Breen, Taubman, Vernon, \& Graubard, 2007; O'Malley et al., 2001). Physician recommendations may prompt women who receive false-positive results to act on feelings of worry and anxiety, thus facilitating return for future screening. In addition to actual barriers to screening (e.g., costs, physician recommendations), similar effects may be found for people's perceived abilities to act (e.g., perceived behavioural control or perceived barriers) (Ajzen, 1985; Janz \& Becker, 1984).

\section{Testing mediational hypotheses}

The model of false-positive test results proposes several mediational hypotheses. While researchers have used a variety of study designs to test mediational hypotheses, strong tests of mediation should establish a temporal chain among predictor, mediator and outcome variables (Frazier, Tix, \& Barron, 2004). The predictor $(X)$ should occur before the mediator variable $(M)$ and $M$ should occur before the outcome $(Y)$. Because measurement of 
constructs is unlikely to coincide with their occurrence, researchers should take special care in understanding the limitations and challenges inherent in the approach they choose. The following sections continue to use the example of false-positive mammography results to illustrate several key considerations when testing the model's mediational hypotheses.

\section{Cross-sectional study designs}

Researchers sometimes test for mediation using cross-sectional study designs that rely on retrospective recall of constructs and behaviours. However, such studies usually preclude establishing a temporal timeline among variables, making them not desirable for testing mediational hypotheses. Thus, findings from cross-sectional studies can be considered only exploratory or suggestive of mediation (Cole \& Maxwell, 2003).

In the context of false-positive mammography results and return for screening, use of crosssectional study design is potentially problematic, because the outcome- $Y$ (whether or not women returned for a subsequent screening and the result of that screening exam) could plausibly influence subject's report of potential mediators $(M)$. For example, women who returned for mammograms $(Y)$ and received normal test results may later report less worry about breast cancer $(M)$ compared to women who had not yet returned for screening. As a result, effects of $M$ on $Y$ would be biased because of this reverse causal pathway and the basis for causal inference would be seriously undermined.

\section{Longitudinal study designs}

Longitudinal designs are preferable for testing mediation models, because they better allow researchers to establish a temporal timeline among variables (Cole \& Maxwell, 2003). The length of time between receipt of a false-positive and assessment of mediators should not be so long that psychological effects of the false-positive result would have dissipated. Studies generally have found that false-positive mammography results impact psychological outcomes anywhere from a few weeks to 36 months after the false-positive experience (Brewer et al., 2007). A related consideration is that this time lag should not be so great that researchers assess mediators $(M)$ well after women return for screening $(Y)$.

It is also possible that the degree to which false-positive test results impact psychological outcomes $(M)$ will vary over time. As a result, the strength of the effect of $X$ on $M$ might not be the same for all time intervals. For studies where the influence of $X$ on $M$ is not stationary, researchers suggest the inclusion of a variety of time intervals over which the mediation process might unfold (Cole \& Maxwell, 2003). That is, rather than assessment of a time-specific mediated effect (the degree to which $M$ at exactly Time 2 mediates the effect of $X$ at exactly Time 1 on $Y$ ), researchers will be more interested in an overall mediated effect - the degree to which $M$ at any time within a specified window mediates the effect of false-positive test results on behaviour.

A final consideration is that a construct might occur at a different time than when a researcher measures it (Cole \& Maxwell, 2003). That is, measures of $Y$ and $M$ might actually assess conditions that began long before the occurrence of $X$ (Weinstein, 2007). As a result, the temporality among variables could be compromised. In the context of false-positive mammograms, some mediators (such as worry about breast cancer) will have existed prior to the occurrence of $X$ (false-positive test result). Women may have worried about breast cancer even before receipt of the mammogram that produced the false-positive result. Therefore, prior levels of $M$ should be controlled if researchers want to determine if changes in the mediating variables influence the outcome. Another possible scenario is that the behaviour represented by $Y$ might precede $X$. Women who consistently return for routine screenings might be more likely to have received false-positive test results. They will have 
undergone more screening exams and thus will have had more opportunities for falsepositive results (Burman, Taplin, Herta, \& Elmore, 1999). Studying a population of homogenous women with respect to their previous screening histories or statistical adjustment for previous screening behaviour would control for this potential source of bias.

\section{Connections to models of health behaviour}

Many aspects of the proposed model, especially the links to mammography uptake, overlap with existing general models of health behaviour. Indeed the conceptualisation of many of these social cognitive models was the inspiration for some of our theorising. For example, the link between perceived likelihood of disease and protective behaviour is central to several theories of health behaviour (Weinstein, 1993) including the Health Belief Model (HBM) (Janz \& Becker, 1984) Extended Parallel Process Model (Witte, 1992, 1994), and Precaution Adoption Process Model (Weinstein \& Sandman, 1992). These models generally propose the greater people perceive their risk of disease, the more likely they will engage in protective behaviour. Although not formally embedded in many of the most commonly used models of health behaviour (Noar \& Zimmerman, 2005), the motivating influence of worry resembles theories about the relationship between emotion and protective behaviour (Leventhal et al., 2003) and also models of stress and coping where emotional responses are proposed to motivate problem-focused coping (Lazarus, 1984). The hypothesis that perceptions of test accuracy should influence health behaviour is similar to perceived efficacy constructs of the Extended Parallel Process Model (Witte, 1992, 1994) and perceived effectiveness in the HBM (Janz \& Becker, 1984).

\section{Significance and implications of the model}

Understanding the influence of false-positive mammography results is increasingly important as we rethink screening guidelines and implement new screening technologies. Researchers estimate that about one-half of USA women will receive false-positive mammography results if tested annually for a decade (Elmore et al., 1998). This proportion would be somewhat lower, but still as high as one third, if women adhere to biennial screening guidelines. Wider implementation of digital mammography might contribute to higher rates of false-positive results, because research suggests digital technology detects larger proportions of breast cancers at the expense of an increased false-positive rate (Skaane, 2009). A better understanding of the long-term psychological and behavioural consequences of receiving false-positive results on screening exams should be a public health priority. While we argue that some psychological reactions to false-positives, such as anxiety and worry, may motivate futures screening, these thoughts are negative to experience and should be minimised through intervention (Barton et al., 2004).

While the model presented in this paper focuses on mammography screening, expanding this model to other screening tests is a promising area of future research. For example, effects elicited by false-positive mammography results for women may be similar to those experienced by men undergoing screening for prostate cancer. False-positive prostate cancer screening test result (PSAs) likely influence men's perceptions of cancer risk, worry and perceptions of test accuracy, although these topics have received little attention. However, unlike mammography screening, the one published study on this topic suggests US men who receive false-positive results on PSAs are less likely to return for subsequent prostate cancer screening compared to men whose results are normal (Ford et al., 2005). While it is possible that perceptions of test inaccuracy or distrust might explain this finding, other factors, such as the risk of sexual side effects that can result from biopsy procedures for positive PSAs and the ambiguous benefits of the test may play important roles. As false-positive test results from cervical and colon cancer screening are also quite common (Croswell et al., 2009; 
Nanda et al., 2000) their effects merit greater study. Another population of interest is breast cancer patients who have survived their disease and are undergoing regular screening and surveillance. False-positive results on routine mammography exams may have an amplified effect on cancer survivors' thoughts, well-being and screening behaviour, although no research we are aware of has explored these issues.

It is also plausible that more complex relationships exist among the constructs presented in the proposed model. For example, Aiken, West, Woodward, Reno, \& Reynolds (1994) longitudinal analyses of HBM constructs showed that perceptions of perceived breast cancer risk lead to more thought about mammography's benefits which, coupled with fewer barriers to screening, influenced use. Examining these possible additional relationships among the constructs presented in our model could be a future area of research.

\section{Summary}

In conclusion, this article proposes a model, informed by empirical evidence, clarifying the relationship between receipt of false-positive mammography results and return for subsequent screening. We propose that false-positive mammography results cause women to think differently about themselves and the screening test. We also argue that these effects can persist several years beyond the false-positive experience - long enough to influence future screening behaviour. While the focus of our model is on mammography screening, it might be applicable to other screening tests and behaviours.

\section{Acknowledgments}

The authors thank Mike Bowling, Erica Breslau, Jo Anne Earp, Barbara Rimer and Talya Salz for input on this article. At the time of this research, Jessica DeFrank, PhD, was funded by the UNC University Cancer Research Fund and the UNC Cancer Care and Quality Training Programme (NCI R25 Grant, CA116339).

\section{References}

Aiken LS, West SG, Woodward CK, Reno RR, Reynolds KD. Increasing screening mammography in asymptomatic women: Evaluation of a second-generation, theory-based program. Health Psychology: Official Journal of the Division of Health Psychology, American Psychological Association. 1994; 13(6):526-538.

Ajzen, I. From intentions to actions: A theory of planned behavior. In: Kuhl, J.; Beckmann, J., editors. Action control: From cognition to behavior. Berlin and New York: Springer-Verlag; 1985. p. 11-40.

Andersen MR, Smith R, Meischke H, Bowen D, Urban N. Breast cancer worry and mammography use by women with and without a family history in a population-based sample. Cancer Epidemiology, Biomarkers \& Prevention. 2003; 12(4):314-320.

Andersen SB, Vejborg I, von Euler-Chelpin M. Participation behaviour following a false positive test in the Copenhagen mammography screening programme. Acta Oncologica (Stockholm, Sweden). 2008; 47(4):550-555.

Aro AR, de Koning HJ, Absetz P, Schreck M. Psychosocial predictors of first attendance for organised mammography screening. Journal of Medical Screening. 1999; 6(2):82-88. [PubMed: 10444726]

Aro AR, Pilvikki Absetz S, van Elderen TM, van der Ploeg E, van der Kamp LJ. False-positive findings in mammography screening induces short-term distress-breast cancer-specific concern prevails longer. European Journal of Cancer (Oxford, England: 1990). 2000; 36(9):1089-1097.

Barton MB, Morley DS, Moore S, Allen JD, Kleinman KP, Emmons KM, Fletcher SW. Decreasing women's anxieties after abnormal mammograms: A controlled trial. Journal of the National Cancer Institute. 2004; 96(7):529-538. [PubMed: 15069115]

Brain K, Henderson BJ, Tyndel S, Bankhead C, Watson E, Clements A, Austoker J. Predictors of breast cancer-related distress following mammography screening in younger women on a family history breast screening programme. Psycho-Oncology. 2008; 17(12):1180-1188. [PubMed: 18506670] 
Brett J, Austoker J. Women who are recalled for further investigation for breast screening:

Psychological consequences 3 years after recall and factors affecting re-attendance. Journal of Public Health Medicine. 2001; 23(4):292-300. [PubMed: 11873891]

Brett J, Bankhead C, Henderson B, Watson E, Austoker J. The psychological impact of mammographic screening. A systematic review. Psycho-Oncology. 2005; 14(11):917-938. [PubMed: 15786514]

Brewer NT, Salz T, Lillie SE. Systematic review: The long-term effects of false-positive mammograms. Annals of Internal Medicine. 2007; 146(7):502-510. [PubMed: 17404352]

Brewer NT, Tzeng JP, Lillie SE, Edwards AS, Peppercorn JM, Rimer BK. Health literacy and cancer risk perception: Implications for genomic risk communication. Medical Decision Making. 2009; 29(2):157-166. [PubMed: 19050227]

Brodersen J, Thorsen H. The long-term effects of false-positive mammograms [Comment]. Annals of Internal Medicine. 2007; 147(10):739. author reply 739-740. [PubMed: 18025451]

Brodersen J, Thorsen H. Consequences of screening in breast cancer (COS-BC): Development of a questionnaire. Scandinavian Journal of Primary Health Care. 2008; 26(4):251-256. [PubMed: 19034808]

Brodersen J, Thorsen H, Cockburn J. The adequacy of measurement of short and long-term consequences of false-positive screening mammography. Journal of Medical Screening. 2004; 11(1):39-44. [PubMed: 15006113]

Bull AR, Campbell MJ. Assessment of the psychological impact of a breast screening programme. The British Journal of Radiology. 1991; 64(762):510-515. [PubMed: 2070180]

Burman ML, Taplin SH, Herta DF, Elmore JG. Effect of false-positive mammograms on interval breast cancer screening in a health maintenance organization. Annals of Internal Medicine. 1999; 131(1):1-6. [PubMed: 10391809]

Champion V, Maraj M, Hui S, Perkins AJ, Tierney W, Menon U, Skinner CS. Comparison of tailored interventions to increase mammography screening in nonadherent older women. Preventive Medicine. 2003; 36(2):150-158. [PubMed: 12590989]

Christiansen CL, Wang F, Barton MB, Kreuter W, Elmore JG, Gelfand AE, Fletcher SW. Predicting the cumulative risk of false-positive mammograms. Journal of the National Cancer Institute. 2000; 92(20):1657-1666. [PubMed: 11036111]

Cole DA, Maxwell SE. Testing mediational models with longitudinal data: Questions and tips in the use of structural equation modeling. Journal of Abnormal Psychology. 2003; 112(4):558-577. [PubMed: 14674869]

Consedine NS, Magai C, Krivoshekova YS, Ryzewicz L, Neugut AI. Fear, anxiety, worry, and breast cancer screening behavior: A critical review. Cancer Epidemiology, Biomarkers \& Prevention. 2004; 13(4):501-510.

Croswell JM, Kramer BS, Kreimer AR, Prorok PC, Xu JL, Baker SG, et al. Cumulative incidence of false-positive results in repeated, multimodal cancer screening. Annals of Family Medicine. 2009; 7(3):212-222. [PubMed: 19433838]

Cyrlak D. Induced costs of low-cost screening mammography. Radiology. 1988; 168(3):661-663. [PubMed: 3406395]

Davey HM, Lim J, Butow PN, Barratt AL, Houssami N, Higginson R. Consumer information materials for diagnostic breast tests: Women's views on information and their understanding of test results. Health Expectations. 2003; 6(4):298-311. [PubMed: 15040792]

Decker KM. Retention of screened women in the Manitoba breast screening program. Canadian Journal of Public Health (Revue Canadienne De Sante Publique). 2008; 99(3):216-220. [PubMed: 18615945]

Elmore JG, Barton MB, Moceri VM, Polk S, Arena PJ, Fletcher SW. Ten-year risk of false positive screening mammograms and clinical breast examinations. The New England Journal of Medicine. 1998; 338(16):1089-1096. [PubMed: 9545356]

Elmore JG, Nakano CY, Koepsell TD, Desnick LM, D’Orsi CJ, Ransohoff DF. International variation in screening mammography interpretations in community-based programs. Journal of the National Cancer Institute. 2003; 95(18):1384-1393. [PubMed: 13130114] 
Fiscella K, Franks P, Clancy CM. Skepticism toward medical care and health care utilization. Medical Care. 1998; 36(2):180-189. [PubMed: 9475472]

Ford ME, Havstad SL, Demers R, Cole Johnson C. Effects of false-positive prostate cancer screening results on subsequent prostate cancer screening behavior. Cancer Epidemiology, Biomarkers \& Prevention. 2005; 14(1):190-194.

Ford ME, Havstad SL, Flickinger L, Johnson CC. Examining the effects of false positive lung cancer screening results on subsequent lung cancer screening adherence. Cancer Epidemiology, Biomarkers \& Prevention. 2003; 12(1):28-33.

Frazier PA, Tix AP, Barron KE. Testing moderator and mediator effects in counseling psychology research. Journal of Counseling Psychology. 2004; 51(1):115-134.

Gigerenzer G, Edwards A. Simple tools for understanding risks: From innumeracy to insight. British Medical Journal. 2003; 327(7417):741-744. [PubMed: 14512488]

Gilbert DT, Tafarodi RW, Malone PS. You can't not believe everything you read. Journal of Personality and Social Psychology. 1993; 65(2):221-233. [PubMed: 8366418]

Gram IT, Lund E, Slenker SE. Quality of life following a false positive mammogram. British Journal of Cancer. 1990; 62(6):1018-1022. [PubMed: 2257206]

Greene AL, Torio CM, Klassen AC. Measuring sustained mammography use by urban AfricanAmerican women. Journal of Community Health. 2005; 30(4):235-251. [PubMed: 15989207]

Hay JL, McCaul KD, Magnan RE. Does worry about breast cancer predict screening behaviors? A meta-analysis of the prospective evidence. Preventive Medicine. 2006; 42(6):401-408. [PubMed: 16626796]

Janz NK, Becker MH. The Health Belief Model: A decade later. Health Education Quarterly. 1984; 11(1):1-47. [PubMed: 6392204]

Katapodi MC, Lee KA, Facione NC, Dodd MJ. Predictors of perceived breast cancer risk and the relation between perceived risk and breast cancer screening: A meta-analytic review. Preventive Medicine. 2004; 38(4):388-402. [PubMed: 15020172]

Kerlikowske K, Grady D, Barclay J, Sickles EA, Eaton A, Ernster V. Positive predictive value of screening mammography by age and family history of breast cancer. JAMA. 1993; 270(20):24442450. [PubMed: 8230621]

Lafata JE, Simpkins J, Lamerato L, Poisson L, Divine G, Johnson CC. The economic impact of falsepositive cancer screens. Cancer Epidemiology, Biomarkers \& Prevention. 2004; 13(12):21262132.

Lampic C, Thurfjell E, Bergh J, Sjoden PO. Short- and long-term anxiety and depression in women recalled after breast cancer screening. European Journal of Cancer (Oxford, England: 1990). 2001; 37(4):463-469.

Lampic C, Thurfjell E, Sjoden PO. The influence of a false-positive mammogram on a woman's subsequent behaviour for detecting breast cancer. European Journal of Cancer (Oxford, England: 1990). 2003; 39(12):1730-1737.

Laveist TA, Isaac LA, Williams KP. Mistrust of health care organizations is associated with underutilization of health services. Health Services Research. 2009; 44:2093-2105. [PubMed: 19732170]

Lazarus, RS.; Folkman, S. Stress, appraisal, and coping. New York: Springer; 1984.

Lerman C, Miller SM, Scarborough R, Hanjani P, Nolte S, Smith D. Adverse psychologic consequences of positive cytologic cervical screening. American Journal of Obstetrics and Gynecology. 1991; 165(3):658-662. [PubMed: 1892194]

Lerman C, Trock B, Rimer BK, Boyce A, Jepson C, Engstrom PF. Psychological and behavioral implications of abnormal mammograms. Annals of Internal Medicine. 1991; 114(8):657-661. [PubMed: 2003712]

Lerman C, Trock B, Rimer BK, Jepson C, Brody D, Boyce A. Psychological side effects of breast cancer screening. Health Psychology. 1991; 10(4):259-267. [PubMed: 1915212]

Leventhal, H.; Brissette, I.; Leventhal, E. The common-sense model of self-regulation of health and illness. In: Cameron, L.; Leventhal, H., editors. The self-regulation of health and illness behaviour. London and New York: Routledge; 2003. p. 42-65. 
Lipkus IM, Halabi S, Strigo TS, Rimer BK. The impact of abnormal mammograms on psychosocial outcomes and subsequent screening. Psycho-Oncology. 2000; 9(5):402-410. [PubMed: 11038478]

Lord CG, Ross L, Lepper MR. Biased assimilation and attitude polarization: The effects of prior theories on subsequently considered evidence. Journal of Personality and Social Psychology. 1979; 37(11):2098-2109.

Mayne L, Earp J. Initial and repeat mammography screening: Different behaviors/different predictors. The Journal of Rural Health. 2003; 19(1):63-71. [PubMed: 12585776]

McCaul KD, Branstetter AD, Schroeder DM, Glasgow RE. What is the relationship between breast cancer risk and mammography screening? A meta-analytic review. Health Psychology. 1996; 15(6):423-429. [PubMed: 8973921]

McCaul, KD.; Mullens, AB. Affect, thought, and self-protective health behavior: The case of worry and cancer screening. In: Suls, JM.; Wallston, KA., editors. Social psychological foundations of health and illness. Malden, MA: Blackwell; 2003. p. 137-168.

Meissner HI, Breen N, Taubman ML, Vernon SW, Graubard BI. Which women aren't getting mammograms and why? (United States). Cancer Causes \& Control: CCC. 2007; 18(1):61-70.

Morwitz VG, Fitzsimons GJ. The mere-measurement effect: Why does measuring intentions change actual behavior? Journal of Consumer Psychology. 2004; 14(1-2):64-74.

Mushlin AI, Kouides RW, Shapiro DE. Estimating the accuracy of screening mammography: A metaanalysis. American Journal of Preventive Medicine. 1998; 14(2):143-153. [PubMed: 9631167]

Nanda K, McCrory DC, Myers ER, Bastian LA, Hasselblad V, Hickey JD, Matchar DB. Accuracy of the papanicolaou test in screening for and follow-up of cervical cytologic abnormalities: A systematic review. Annals of Internal Medicine. 2000; 132(10):810-819. [PubMed: 10819705]

Noar SM, Zimmerman RS. Health behavior theory and cumulative knowledge regarding health behaviors: Are we moving in the right direction? Health Education Research. 2005; 20(3):275290. [PubMed: 15632099]

O'Malley MS, Earp JA, Hawley ST, Schell MJ, Mathews HF, Mitchell J. The association of race/ ethnicity, socioeconomic status, and physician recommendation for mammography: Who gets the message about breast cancer screening? American Journal of Public Health. 2001; 91(1):49-54. [PubMed: 11189825]

Padgett DK, Yedidia MJ, Kerner J, Mandelblatt J. The emotional consequences of false positive mammography: African-American women's reactions in their own words. Women \& Health. 2001; 33(3-4):1-14.

Peters E, Hibbard J, Slovic P, Dieckmann N. Numeracy skill and the communication, comprehension, and use of risk-benefit information. Health Affairs. 2007; 26(3):741-748. [PubMed: 17485752]

Pisano ED, Earp JA, Gallant TL. Screening mammography behavior after a false positive mammogram. Cancer Detection and Prevention. 1998; 22(2):161-167. [PubMed: 9544437]

Randall G, Molloy GJ, Steptoe A. The impact of an acute cardiac event on the partners of patients. A systematic review. Health Psychology Review. 2009; 3:1-84.

Ransohoff DF, McNaughton Collins M, Fowler FJ. Why is prostate cancer screening so common when the evidence is so uncertain? A system without negative feedback. The American Journal of Medicine. 2002; 113(8):663-667. [PubMed: 12505117]

Rauscher GH, Earp JA, O'Malley M. Relation between intervention exposures, changes in attitudes, and mammography use in the North Carolina breast cancer screening program. Cancer Epidemiology, Biomarkers \& Prevention. 2004; 13(5):741-747.

Reyna VF, Nelson WL, Han PK, Dieckmann NF. How numeracy influences risk comprehension and medical decision making. Psychological Bulletin. 2009; 135(6):943-973. [PubMed: 19883143]

Rimer BK, Bluman LG. The psychosocial consequences of mammography. Journal of the National Cancer Institute Monographs. 1997; (22):131-138. [PubMed: 9709289]

Rimer BK, Conaway MR, Lyna PR, Rakowski W, Woods-Powell CT, Tessaro I, Yarnall KS, Barber LT. Cancer screening practices among women in a community health center population. American Journal of Preventive Medicine. 1996; 12(5):351-357. [PubMed: 8909646]

Salz T, Richman AR, Brewer NT. The long-term consequences of false-positive mammograms on outcomes specific to breast cancer. Psycho-Oncology. 2010 Forthcoming. 
Scaf-Klomp W, Sanderman R, van de Wiel HB, Otter R, van den Heuvel WJ. Distressed or relieved? Psychological side effects of breast cancer screening in the Netherlands. Journal of Epidemiology and Community Health. 1997; 51(6):705-710. [PubMed: 9519137]

Schwartz LM, Woloshin S, Fowler FJ Jr, Welch HG. Enthusiasm for cancer screening in the United States. JAMA: The Journal of the American Medical Association. 2004; 291(1):71-78. [PubMed: 14709578]

Skaane P. Studies comparing screen-film mammography and full-field digital mammography in breast cancer screening: Updated review. Acta Radiologica (Stockholm, Sweden: 1987). 2009; 50(1):314.

Smith-Bindman R, Chu PW, Miglioretti DL, Sickles EA, Blanks R, Ballard-Barbash R, et al. Comparison of screening mammography in the United States and the United Kingdom. JAMA: The Journal of the American Medical Association. 2003; 290(16):2129-2137. [PubMed: 14570948]

Strack F, Mussweiler T. Explaining the enigmatic anchoring effect: Mechanisms of selective accessibility. Journal of Personality and Social Psychology. 1997; 73(3):437-446.

Thoolen B, De Ridder D, Bensing J, Gorter K, Rutten G. No worries, no impact? A systematic review of emotional, cognitive, and behavioural responses to the diagnosis of type 2 diabetes. Health Psychology Review. 2008; 2:65-93.

Vernon SW. Risk perception and risk communication for cancer screening behaviors: A review. Journal of the National Cancer Institute Monographs. 1999; 25:101-119. [PubMed: 10854465]

Weinstein ND. Testing four competing theories of health-protective behavior. Health Psychology. 1993; 12(4):324-333. [PubMed: 8404807]

Weinstein ND. Misleading tests of health behavior theories. Annals of Behavioral Medicine: A Publication of the Society of Behavioral Medicine. 2007; 33(1):1-10. [PubMed: 17291165]

Weinstein ND, Sandman PM. A model of the precaution adoption process: Evidence from home radon testing. Health Psychology. 1992; 11(3):1-10.

Witte K. Putting the fear back into fear appeals: The Extended Parallel Process Model. Communications Monographs. 1992; 59:329-348.

Witte K. Fear control and danger control. A test of the extended parallel process model (EPPM). Communication Monographs. 1994; 61(2):113-134.

Yankaskas BC, Klabunde CN, Ancelle-Park R, Renner G, Wang H, Fracheboud J, Pou G, Bulliard JL. International comparison of performance measures for screening mammography: Can it be done? Journal of Medical Screening. 2004; 11(4):187-193. [PubMed: 15624239] 


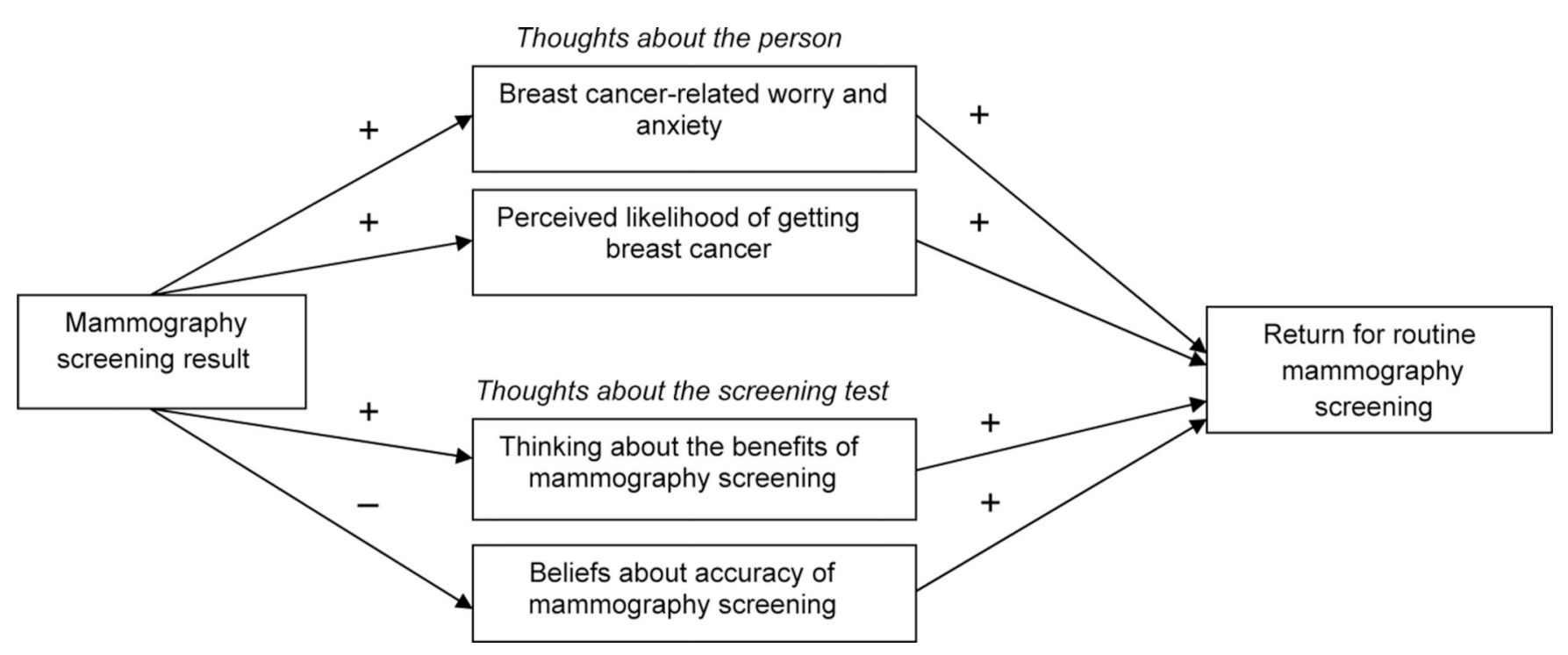

Figure 1.

Model of effects of false-positive mammography screening results 


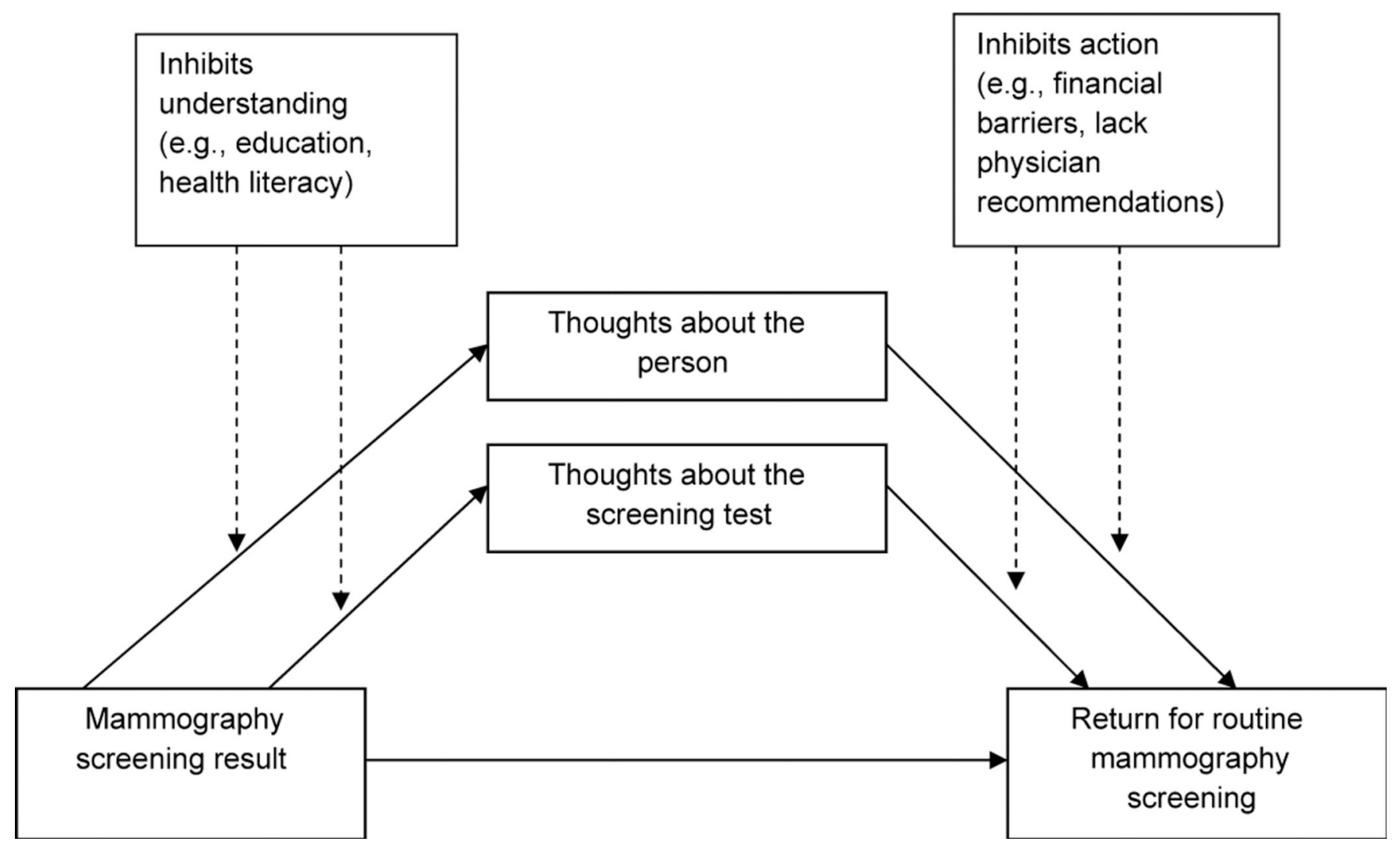

Figure 2.

Moderating factors on association between false-positive mammography results and return for mammography screening 